This item was submitted to Loughborough's Research Repository by the author.

Items in Figshare are protected by copyright, with all rights reserved, unless otherwise indicated.

\title{
Eco-intelligent factories: Timescales for environmental decision support
}

PLEASE CITE THE PUBLISHED VERSION

http://www.springer.com/gb/book/9783319570778

\section{PUBLISHER}

(C) Springer

\section{VERSION}

AM (Accepted Manuscript)

\section{PUBLISHER STATEMENT}

This work is made available according to the conditions of the Creative Commons Attribution-NonCommercialNoDerivatives 4.0 International (CC BY-NC-ND 4.0) licence. Full details of this licence are available at: https://creativecommons.org/licenses/by-nc-nd/4.0/

\section{LICENCE}

CC BY-NC-ND 4.0

\section{REPOSITORY RECORD}

Woolley, Elliot, Alessandro Simeone, and Shahin Rahimifard. 2019. "Eco-intelligent Factories: Timescales for Environmental Decision Support". figshare. https://hdl.handle.net/2134/24088. 


\title{
Eco-Intelligent Factories: Timescales for Environmental Decision Support
}

\author{
Elliot Woolley ${ }^{1}$, Alessandro Simeone ${ }^{1}$ and Shahin Rahimifard ${ }^{1}$ \\ ${ }^{1}$ Centre for Sustainable Manufacturing and Recycling \\ Technologies, Wolfson School of Mechanical, Electrical and \\ Manufacturing Engineering, Loughborough University, UK \\ \{e.b.woolley, a.simeone, s.rahimifard\}@lboro.ac.uk
}

\begin{abstract}
Manufacturing decisions are currently made based on considerations of cost, time and quality. However there is increasing pressure to also routinely incorporate environmental considerations into the decision making processes. Despite the existence of a number of tools for environmental analysis of manufacturing activities, there does not appear to be a structured approach for generating relevant environmental information that can be fed into manufacturing decision making. This research proposes an overarching structure that leads to three approaches, pertaining to different timescales that enable the generation of environmental information, suitable for consideration during decision making. The approaches are demonstrated through three industrial case studies.
\end{abstract}

Keywords: manufacturing $\cdot$ environmental impact $\cdot$ decision support $\cdot$ artificial intelligence

\section{$1 \quad$ Introduction}

Globally, factories account for roughly one third of energy use [1], and one third of energy related $\mathrm{CO}_{2}$ production [2]. This is in addition to other air, land and water emissions, chemical use and demand for materials. The world's factories are a hotspot of human induced environmental impacts and therefore require effective environmental management programmes.

In contrast to this need, current manufacturing management systems and related decision making are optimised for cost effectiveness, time efficiency (productivity) and quality control [3], but not environmental impacts. These complex networks of data and information systems enable manufacturers to remain competitive by making informed short-term decisions and by forecasting over longer time scales. However, despite legislative developments in this area (e.g. [4]), environmental considerations are not routinely included in this planning (Fig. 1), and it is becoming clear that their inclusion could lead to a significant reduction in environmental impacts [5]. In this work, an analysis of industrial decision making is contrasted with modern approaches for generation of consideration of environmental data in manufacturing decisions. 


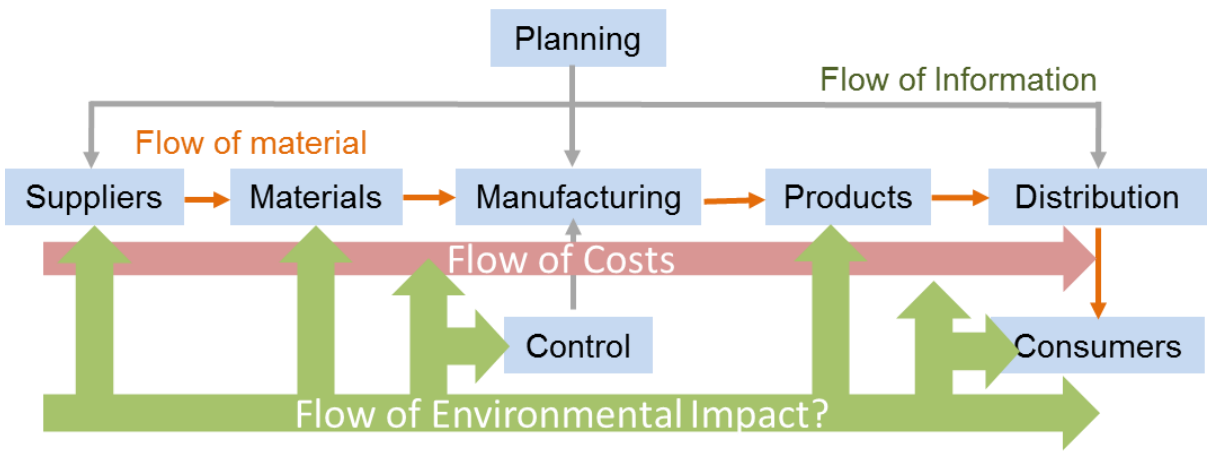

Fig. 1. Opportunities for the inclusion of environmentally related data in industrial decision making.

A gap in the availability of environmental data is identified, with a three timescale (short, medium and long) approach proposed to enable more systematic generation of environmental information to feed into decision making within manufacturing.

Correspondingly a number of case studies are presented demonstrating the generation of eco-intelligent information across these timescales. The paper concludes with a discussion of how the approaches described in this work can be applied more routinely to the wider industry.

\section{$2 \quad$ Literature review}

\subsection{Manufacturing decision making}

Enterprise Resource Planning (ERP) is the generic term used for modern manufacturing management infrastructures (not just the software component) whereby there is one set of rules for balancing supply and demand, linking customers and suppliers in one chain, employing proven business processes for decision making, and providing cross-functional integration across departments and activities [6]. Because of its effectiveness, some form of ERP can be found in almost every manufacturing company worldwide, and the provision of the software and support for ERP (e.g SAP, Oracle,) is in itself a global multi-billion dollar business [7]. Due to the perceived low economic value of environmental performance, none of these systems are configured to allow comprehensive consideration of environmental impacts in decision making. In order to be able to consider environmental impacts in production planning and control, there is a need to measure and compare environmental metrics but these are difficult to define and vary widely depending upon specific manufacturing activities.

Clearly within manufacturing companies there is a substantial amount of information that is created on a daily basis which is used across many departments to enable efficient, profitable operation of their production plants [8]. Despite much of this data being used to support manufacturing activities across production, logistics, customer promising, etc., there are other, environmentally focused, decisions that could 
be supported using this data. For example, by comparing production cell energy consumption against product throughput would yield an indication of product energy embedded by that cell - which can be used as a benchmark to highlight and investigate periods of over-consumption. By utilising this latent capability in environmentally related data, there are often opportunities for reducing environmental impact [9].

\subsection{Environmental information}

The idea of incorporating environmental considerations into manufacturing activities is not new. The establishment of Environmental Management Systems (EMS) have allowed manufacturers to make decisions on their activities with respect to environmental performance [10]. In addition there are a number of both complex and simplified LCA type tools (SimaPro [PRé Consultants], CES [Granta Design], etc.) which can be and are used by manufacturing companies to assess the environmental impact of the products they make, and thus allow them to improve product design ('design for $\mathrm{X}$ ' approaches) to reduce resource consumption and avoid other negative environmental impacts [11]. However LCA tools still only support slow, progressive improvements to manufacturing activities rather than optimising in the shorter term.

Not only is there a complexity in understanding and implementing the soft (information) side of incorporating environmental considerations into decision making, but there are issues regarding collecting or accessing sufficient information (both realtime and longer term) to understand existing performance and thus influence decision in planning and control. Such a network of information within a manufacturing enterprise is typically only partially present. In particular the problems manufacturers face with real-time energy metering, management and optimization has been addressed [12] [13], and its relative low importance (in management agendas) coupled with a range of technical and economic implications. In reality, there is a lot of usable data generated within factories, but without the infrastructure to interpret and communicate eco-performance metrics, it is not possible to influence operation and planning decisions.

As a sign of progress within industry, smart metering has been used to help inform decisions by tracking not only the total electrical work and consumed energy, but also the characteristics of specific power consumption over time [14]. Subsequently, research has focused on smart metering systems which involve the use of sensors, processors and analysers to capture, transfer, identify and resolve energy and resource flows in manufacturing systems [15]. Unfortunately however, although some of this information could be used for the assessment of environmental impact, it currently is not due to the lack a suitable infrastructure.

This highlights a need for a methodical approach to information gathering within factories, and for decision makers to have access to appropriate data, and be equipped with the ability to process this data such that it can be fed into decision making processes. Only through these capabilities can manufacturers have the opportunity to improve their environmental performance through improved decision making. 


\section{Eco-intelligent information}

Manufacturing decisions require the varied approaches to information processing depending upon the level at which they are taken [8] - clearly manufacturing decision at the machine level will have different requirements to those taken at the enterprise level as has been reported for manufacturing energy management [16]. Therefore when considering the generation of environmental data to feed into decision-making, a range of timescales (roughly corresponding to different manufacturing levels) with appropriate methodologies must be defined. In the current research, manufacturing decisions are segregated into short, medium, and long timescales pertaining to seconds-hours, hours-months and months-years respectively.

The fundamental thesis being that short-term decisions (such as machine optimisation) require the availability of near real-time data for increased autonomy, medium term decisions (such as maintenance scheduling) require suitable modelling approaches based on appropriate key performance indicators (KPI), whilst long term decisions (such as heavy investments in capital equipment) require forecasting of future impacts. The proposed structure for eco-intelligent information generation is shown in Fig. 2.

For the three different timescales the data requirements and processing into information are quite different. There will be variations in the type of data, amount of data, speed of acquisition and processing required, accuracy and complexity, repetition rate, use of intelligence (natural or artificial), importance to a company amongst many others. It is therefore not suitable to consider all decisions using same approach and consequently three approaches relating to the different timescales are presented and described in the remainder of this section.

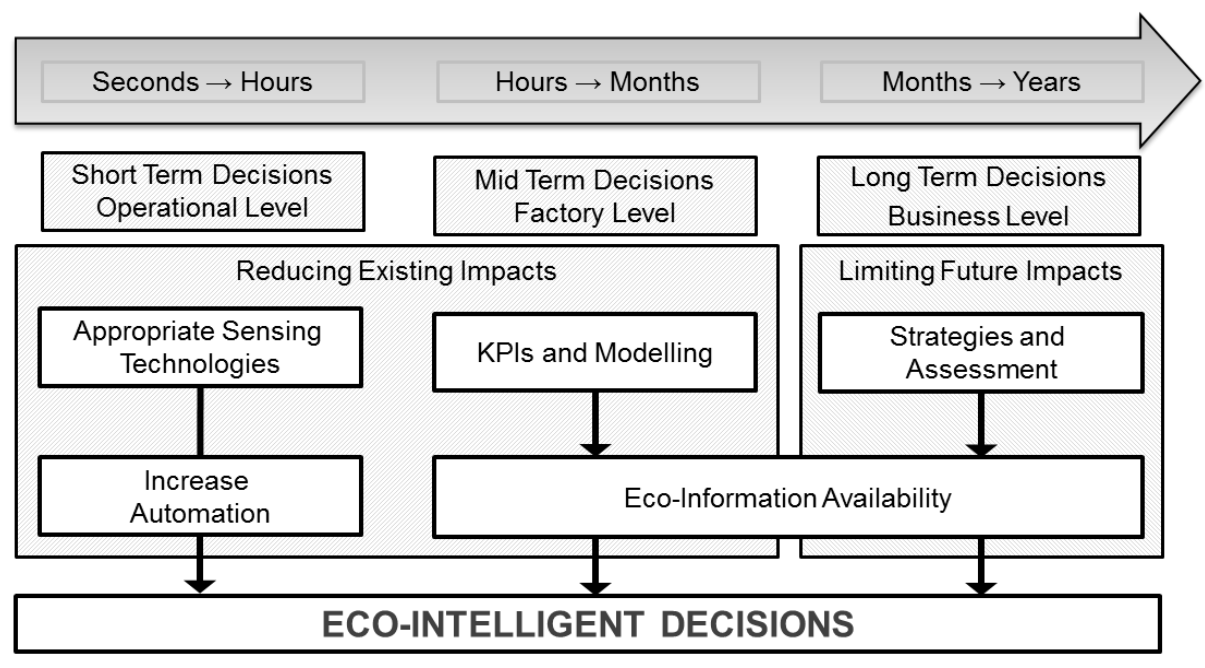

Fig. 2. Eco-intelligent information generation 


\subsection{Short-term decision making}

Within the short term decision making timescale the research scope seeks to minimise a set of environmental factors in a manufacturing process by monitoring specific variables using the most appropriate sensing units, with the possibility of using intelligent decision making support systems.

The first step of the approach is the analysis of the manufacturing process under investigation. This phase is aimed at identifying the aspects of the process and highlighting the related environmental impacts. The problem definition phase results in the identification of the environmental factors to be minimised.

At this point, further consideration about the process needs to be undertaken, classifying which variables can be actively controlled and which variables can be monitored. The sensing unit selection considers the physical and chemical aspects of the process, taking into account commercial availability. Prior to any industrial implementation, the eco-intelligent process monitoring approach requires extensive experimental work in order to calibrate the system and to obtain reliable, repeatable results.

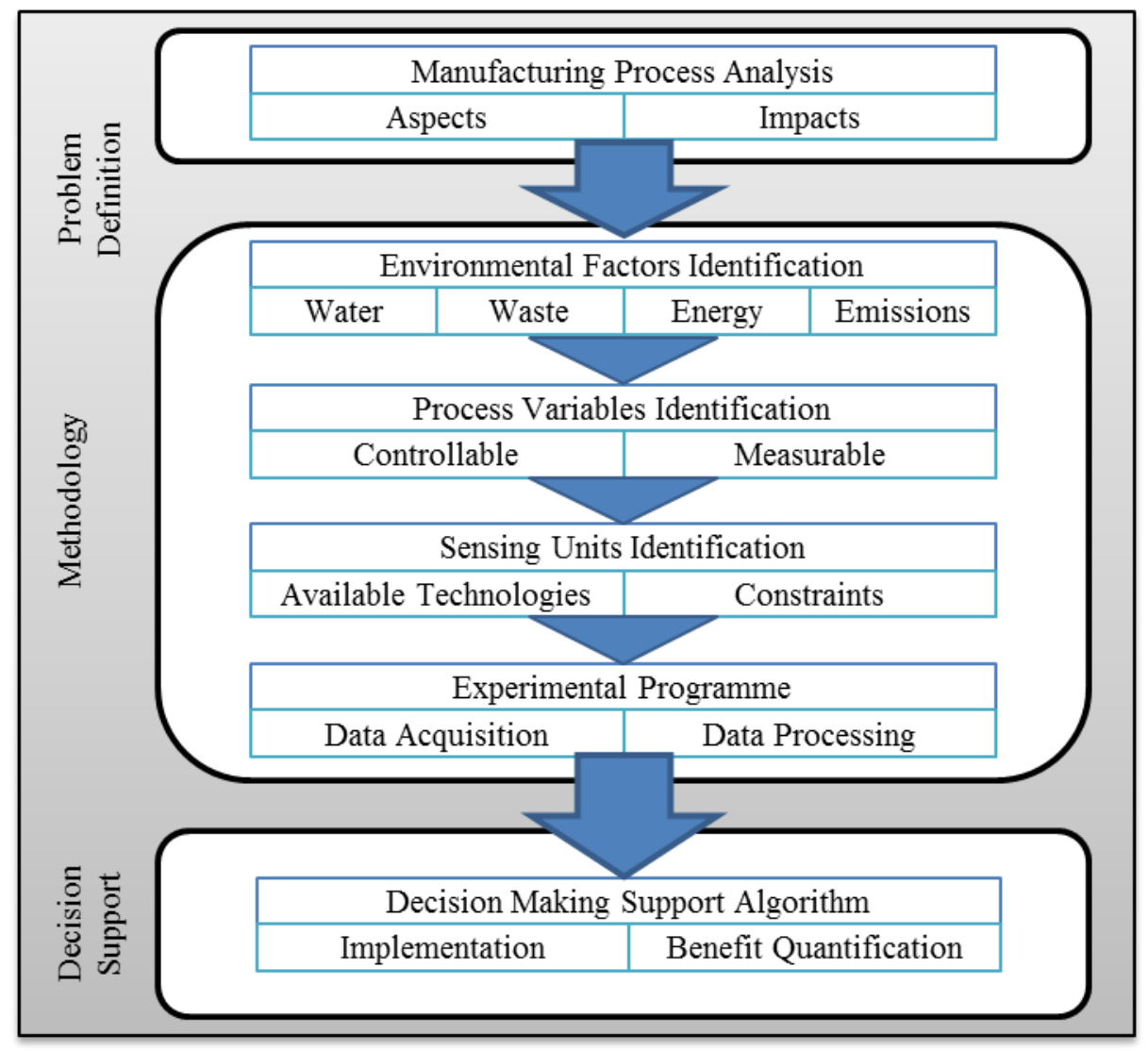

Fig. 3. Short-term decision making support framework 
Once the sensing units have been validated, the experimental setup can be defined, along with a comprehensive experimental plan [17]. The data processing procedure is finalised to extract important features to transform data into useful information [18]. The most common methodologies involve time domain analysis, such as statistical features [19] and Principal Components Analysis (PCA). Whenever time domain features are not suitable, an alternative approach is the frequency domain analysis, such as Wavelet Transform [20].

In terms of decision making support systems and paradigms, neural networks are mainly used for pattern recognition, time series prediction and data fitting [21,22]. Other DM support systems include Fuzzy Logic paradigms [23], Genetic Algorithms (GA) [24], and Ant Colony Optimisation (ACO) [25].

The decision support algorithm will be implemented using the processed data and will generate a result.

\subsection{Medium-term decision making}

The problem definition comprises of a comprehensive analysis of the manufacturing process or system and is required to understand the aspects and the related environmental impacts.

The proposed methodology starts with a characterisation of the environmental drivers to take into account. The next step is the problem formulation: here, the framework aims at the identification of boundaries and targets according to the problem description. In this respect, taking into account the nature of the problem, firstly identify the decision variables, paying particular attention to units, and utilise them to formulate the objective function.

Analogously, formulate the constraints, either logical or explicit to the problem description by expressing them in terms of decision variables. At this point it is possible to identify the data needed for the objective function and constraints.

The model identification is crucial phase of information generation for mediumterm decisions as it describes the structure of the problem and allows the definition of key performance indicators (KPIs).

According to the specific task, the identification of a suitable algorithm to solve the optimisation problem must be carried out. The most common categories of optimisation algorithms, are the finitely terminating algorithms, such as Simplex [26], the iterative methods, e.g. Conjugate Gradient [27], and the heuristic methods, such as Genetic Algorithms [28] and Ant Colony Optimisation [29]. In this phase, the algorithm must be adapted to the case study, considering the aspects highlighted in the first steps of the framework.

A critical step in the optimisation process is the presentation of the solution in a concise and comprehensible summary for stakeholders. In this phase, the results generated need to be effectively comparable in terms of environmental performance in order to quantify the benefit obtained with the optimisation. 


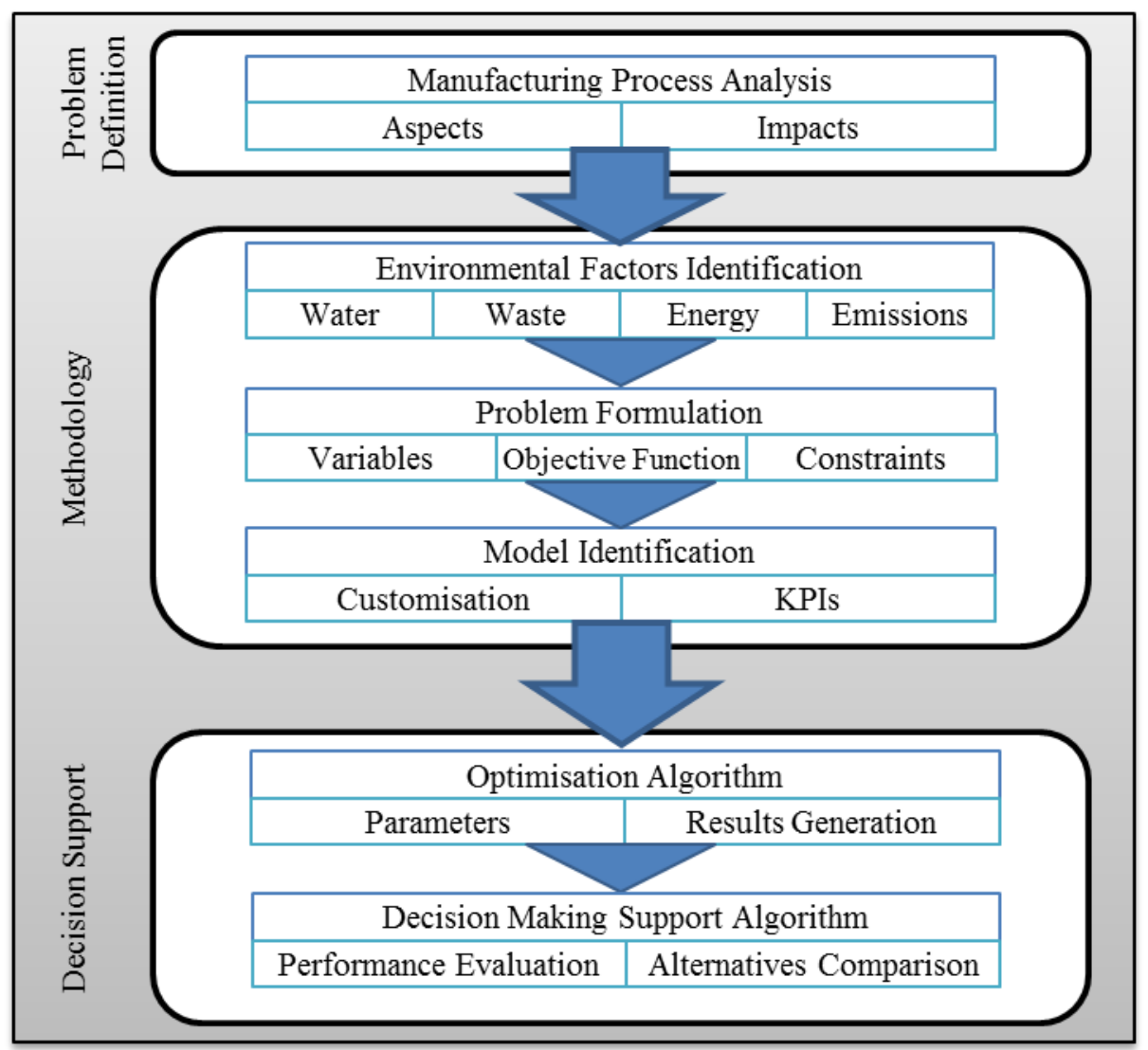

Fig. 4. Medium-term decision making support framework

\subsection{Long term decision making}

There is a need to ensure that the outcomes of environmentally focussed strategic decisions, made over long timescales are in alignment with the greater business strategy [30]. However, in contrast to short and medium term decisions, rather than attributing environmental impact to existing processes or activities of an enterprise, it is more appropriate to forecast and attribute environmental impact to activities required to support and deliver a new business activities. Therefore the first and most difficult phase of the process is planning, which incorporates the definition of the scope of the analysis (the decision in question) and sets the boundaries of consideration (e.g. timescales, areas of business, lifecycle stages) as shown in Fig. 5.

Defining the scope, allows a comparison of different strategies that fulfil the same business need and thus allows a certain level of creativity within long-term decision making. Devising the potential strategies to overcome the problem can only be undertaken by an appropriate team from within a company and will be highly problem specific. Such guidance is outside the scope of this work. 


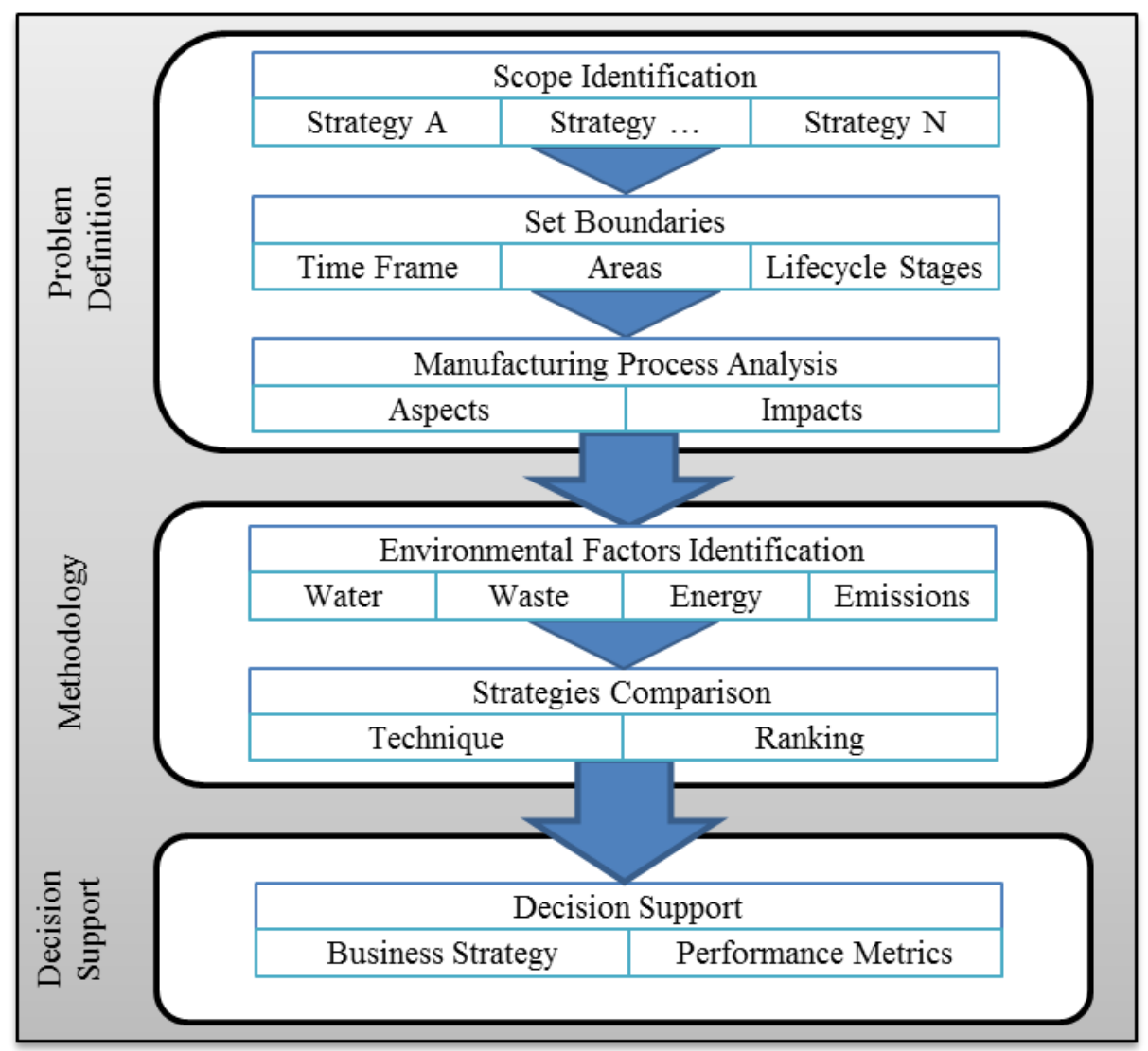

Fig. 5. Long-term decision making support framework

Once potential strategies have been established, the boundary conditions, as described above, allow the identification and quantification of aspects and impacts associated with those solutions. Analysis of the aspects across the different manufacturing levels and lifecycle stages can be undertaken in a systematic manner (see [31] for example). There are a number of tools that assist in the evaluation of environmental impacts, such as LCA and EMS, as described in section 2.2.

Depending upon information generated and the particular impacts considered and appropriate technique for comparison of results [32] should be used and ranking of the potential strategies carried out. The strategies with the best environmental performances should be compared against the broader business strategy before being considered alongside economic and social performance metrics. Outcomes from the implementation of the strategy can be used to feed back into future long-term decision making analysis. 


\section{Case studies}

The following brief case examples demonstrate the application of the application of the eco-intelligent methodologies presented in section 3 .

\subsection{Clean-in-place monitoring - Short term}

Clean-in-place (CIP) is a widely used technique applied to clean industrial equipment without disassembly [33]. Cleaning food deposits, which contain both proteins and minerals, is a complex process that involves interactions between surface, deposits and detergent. It requires a multistage process, having many steps that may be controlled by shear stress, mass transfer, and chemical reaction [33].

Existing CIP processes are time intensive and waste large amounts of energy, water, and chemicals $[34,35]$. Furthermore, it is estimated that on average, a food and beverage plant will spend $20 \%$ of each day on cleaning equipment, which represents significant downtime for a plant [35].

The purpose of this case study is to reduce the cleaning time, so it is necessary to monitor the food traces left within the process tank (Fig. 6). Due to the chemical composition of the food deposit to be monitored, (in this case) milk proteins, the sensing unit selected was a digital camera endowed with UV light set [36].

Data acquisition for this case study consists in the acquisition of a series of digital images, through a time-lapse technology. Data processing is needed to assess the surface fouling level within each digital image and allow the monitoring of the cleaning process. Image processing algorithms based on image segmentation and thresholding [37] were employed for the quantification of remaining fouling.

The decision making associated to this research aims at optimising the cleaning process and is specifically required to understand when each phase of the cleaning process becomes redundant and automatically switch to the next phase.

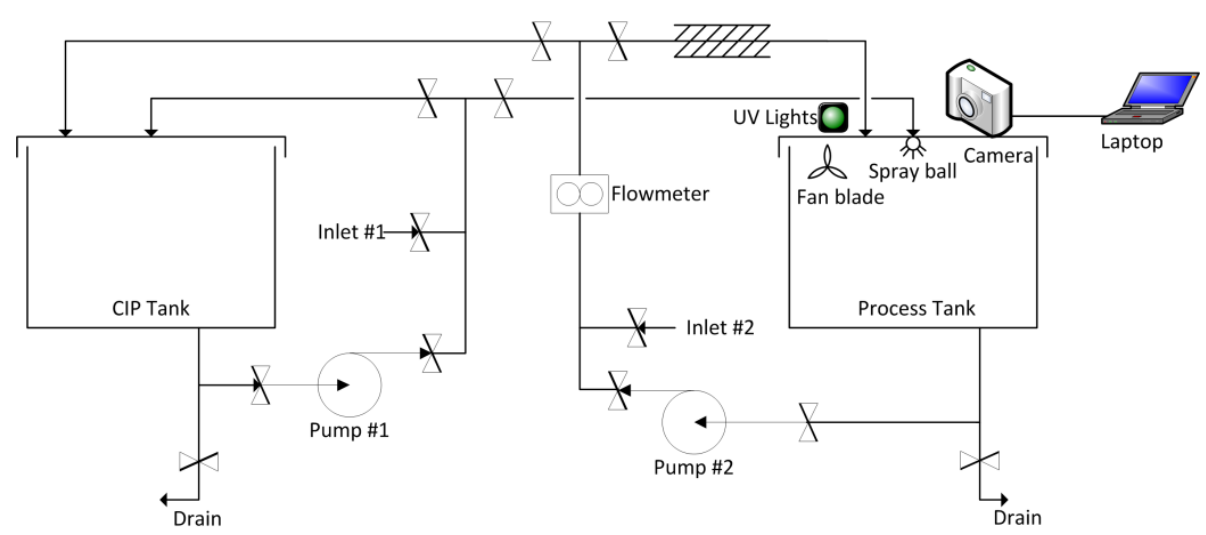

Fig. 6. Clean-in-place experimental rig scheme 


\subsection{Production scheduling - Medium term}

In a food manufacturing plant, an inventory of 50 products was considered. An important qualitative feature of many of the materials in the inventory was that they were a potentially hazardous contaminant if carried over between different production runs. These materials were categorised into multiple different types of Potentially Cross Contaminating Materials (PCCM). The content of each PCCM in each product was designated according to content levels $0-3$. The changeover cleaning protocols, defined by the PCCM content of the former and latter product in a scheduled sequence, is defined in [24]. In this case study the identification of the environmental factor is straight forward, hence the cumulative change over time required (which includes water, energy and other overheads) was used as a proxy environmental impact for overall resource consumption. The production sequence is to be optimized for minimal cumulative resource consumption during changeovers.

Finding the optimal sequence of products with minimised resource consumption was determined to be analogous to the asymmetric travelling salesman problem (ATSP) [24], where each product was represented by a node and the 'distance travelled' between nodes was represented by the changeover cleaning time. With the model identified, expedient solving of the ATSP in this context was approached using a genetic algorithm (GA) [24], which enables the determination of a near optimal solution of complex problems using feasible computing resources.

The GA generated an optimal sequence for 50 products with the minimum changeover cleaning time requirement. Repeat implementation of the GA provides alternative product sequences with equivalent total cleaning time. In this way, a selection of optimum sequences may be performed.

\subsection{Energy efficient business modelling - Long term}

One of the long-term decisions faced by modern manufacturing companies is how best to deliver value into the market. An increasing number of companies are moving towards the delivery of product service systems (PSS) in place of the more traditional make-sell business model [38]. PSSs have many potential economic, social and environmental advantages. However, it is not always clear as to how beneficial a PSS may be, if at all, in comparison to the make-sell alternative.

In this example a comparison of different business strategies for the provision of steel roofing is made, with a particular focus on lifecycle energy requirements. In one strategy the company supplies steel roofing panels via a traditional make-sell business model, and in the other, supplies identical roof panels via a PSS business model. In the latter instance, the manufacturer is responsible for the panels' maintenance throughout their lifetime plus their end-of-life (EoL) recovery.

For fair comparison, the performance metric is set as energy per square meter per year $\left(\mathrm{MJ} / \mathrm{m}^{2} \mathrm{yr}\right)$ and the scope includes manufacture of the panels, use (maintenance) and end-of-life recovery. In addition, the lifetime of the steel roofing for the make-sell and PSS business strategies has been assumed to be 15 and 25 years respectively; the 
PSS roofing having, on average, an extended lifetime due to a regular maintenance schedule.

The energy requirement per square-metre per year of the roofing for the two business strategies is shown in Table 1.

Table 1. Energy requirements considered through product life cycle for comparison between make-sell and PSS business strategies for steel roofing

\begin{tabular}{|c|c|c|}
\hline Energy Contributor & Make-Sell & PSS \\
\hline \multicolumn{3}{|l|}{ Manufacture } \\
\hline Production Energy & $33 \mathrm{MJ} / \mathrm{m}^{2 *}$ & $33 \mathrm{MJ} / \mathrm{m}^{2 *}$ \\
\hline$\Sigma$ (Process Energy + Plant Energy) & $145 \mathrm{MJ} / \mathrm{m}^{2 \#}$ & $145 \mathrm{MJ} / \mathrm{m}^{2 \#}$ \\
\hline ¿Corporation Energy & $2 \mathrm{MJ} / \mathrm{m}^{2 \#}$ & $4 \mathrm{MJ} / \mathrm{m}^{2 \&}$ \\
\hline Use (maintenance) & \multirow{5}{*}{$N / A$} & \\
\hline 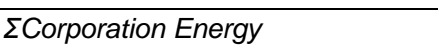 & & $2 \mathrm{MJ} / \mathrm{m}^{2} \mathrm{yr}^{\mathrm{q}}$ \\
\hline End of Life & & \\
\hline Production Energy & & $-48 \mathrm{MJ} / \mathrm{m}^{2 \#}$ \\
\hline ¿Corporation Energy & & $4 \mathrm{MJ} / \mathrm{m}^{2 \&}$ \\
\hline Lifetime of panel & $15 \mathrm{yr}$ & $25 \mathrm{yr}$ \\
\hline Performance metric & $12 \mathrm{MJ} / \mathrm{m}^{2} \mathrm{yr}$ & $7.5 \mathrm{MJ} / \mathrm{m}^{2} \mathrm{yr}$ \\
\hline
\end{tabular}

The energy demand for the manufacturing stage of the product represents the largest energy outlay for the company, and so preserving this investment in energy (through the use of additional energy during use and EoL) by adopting a PSS business strategy becomes beneficial from an energy consumption standpoint.

Based on the analysis of energy requirements for each strategy, a decision is likely to be made to proceed with the PSS business model. In this exemplifying study, only one performance metric was considered: in a more detailed application it is likely that a greater number of indicators would need to be calculated, considered and compared with the wider business strategy.

\section{$5 \quad$ Concluding discussion}

There is a need to more routinely incorporate eco-intelligent information into manufacturing decision making if the industry is to reduce its environmental impacts whilst still meeting the need of consumers. Three approaches for the generation of ecointelligent information have been described that related to different types of manufacturing decision (based on varying timescales). For short-term decisions (seconds to hours) understanding the requirements for sensing and automation are important task. For medium term decisions (hours to months) developing KPIs and associated data models is of primary importance. In contrast, for longer term decisions (months to years) the key challenge is in the problem definition and setting of system boundaries. 
Each approach has been presented and demonstrated using three industrial case examples.

In summary the possibility of routinely incorporating environmental information into manufacturing decision making across all timescales is possible, but requires markedly different approaches. Precisely how to compare eco-intelligent information with economic and social considerations, remains an active topic of global research.

\section{References}

1. International Energy Agency. Key world energy statistics [Internet]. Key world energy statistics. 2016. Available from: http://www.iea.org/statistics/statisticssearch/

2. Allwood J, Cullen J. Sustainable materials - with both eyes open. Cambridge: UIT Cambridge; 2012.f

3. Öker F, Adıgüzel H. Time-Driven Activity-Based Costing: An Implementation in a Manufacturing Company. J Corp Account Financ [Internet]. 2016 Mar 15 [cited 2016 Nov 25];27(3):39-56. Available from: http://doi.wiley.com/10.1002/jcaf.22144

4. U.N. United Nations Framework Convention on Climate Change [Internet]. Vol. 21, Paris Agreement C.N.63.2016.TREATIES-XXVII.7.d. 2016. Available from: https://treaties.un.org/doc/Publication/MTDSG/Volume II/Chapter XXVII/XXVII-7d.en.pdf

5. Epstein MJ, Buhovac AR, Yuthas K. Managing Social, Environmental and Financial Performance Simultaneously. Long Range Plann. 2015;48(1):35-45.

6. Wallace TF, Kremzar MH. AM ERP : Making It Happen Resource Planning [Internet]. New York. 2001. 385 p. Available from: http://cyberrvr.weebly.com/uploads/5/9/7/8/5978545/wiley__erp_making_it_happen.pdf

7. Holsapple CW, Sena MP. ERP plans and decision-support benefits. Vol. 38, Decision Support Systems. 2005. p. 575-90.

8. Vijayaraghavan A, Dornfeld D. Automated energy monitoring of machine tools. CIRP Ann - Manuf Technol. 2010;59(1):21-4.

9. Rahimifard S, Seow Y, Childs T. Minimising embodied product energy to support energy efficient manufacturing. CIRP Ann - Manuf Technol. 2010;59(1):25-8.

10. Melnyk S. Assessing the impact of environmental management systems on corporate and environmental performance. J Oper Manag [Internet]. 2003 May [cited 2016 Nov 14];21(3):329-51. Available from: https://scholars.opb.msu.edu/en/publications/assessing-the-impact-of-environmentalmanagement-systems-on-corpo-3

11. Fiksel J, Wapman K. How to design for environment and minimize life cycle cost. Proc 1994 IEEE Int Symp Electron Environ [Internet]. 1994;75-80. Available from: http://ieeexplore.ieee.org/articleDetails.jsp?arnumber $=337290$

12. Wenzel K, Riegel J, Schlegel A, Putz M. Semantic web based dynamic energy analysis and forecasts in manufacturing engineering. In: Glocalized Solutions for Sustainability in Manufacturing. Springer; 2011. p. 507-12.

13. Kara S, Bogdanski G, Li W. Electricity metering and monitoring in manufacturing 
systems. In: Glocalized Solutions for Sustainability in Manufacturing - Proceedings of the 18th CIRP International Conference on Life Cycle Engineering. 2011. p. 1-10.

14. Müller E, Engelmann J, Löffler T, Strauch J. Energieeffiziente Fabriken planen und betreiben [Internet]. Berlin, Heidelberg: Springer Berlin Heidelberg; 2009 [cited 2016 Nov 14]. Available from: http://link.springer.com/10.1007/978-3-540-89644-9

15. Karnouskos S, Izmaylova A. Simulation of web service enabled smart meters in an event-based infrastructure. In: IEEE International Conference on Industrial Informatics (INDIN). 2009. p. 125-30.

16. Woolley E, Seow, Yingying, Arinez, Jorge, Rahimifard S. The Changing Landscape of Energy Management in Manufacturing. In: Llamas Moya B, Pous J, editors. Greenhouse Gases. 2016.

17. Byrne DM, Taguchi S. The Taguchi approach to parameter design. Qual Prog. 1987;19-26.

18. Guyon I, Elisseeff A. An Introduction to Feature Extraction [Internet]. Vol. 207, Feature Extraction - Foundations and Applications. 2006. 740 p. Available from: http://www.springerlink.com/content/j847w74269401u31/\%5Cnhttp://link.springer.co $\mathrm{m} / 10.1007 / 978-3-540-35488-8$

19. Segreto T, Simeone A, Teti R. Sensor fusion for tool state classification in nickel superalloy high performance cutting. In: Procedia CIRP. 2012. p. 593-8.

20. Karam S, Teti R. Wavelet transform feature extraction for chip form recognition during carbon steel turning. In: Procedia CIRP. 2013. p. 97-102.

21. Simeone A, Watson N, Sterritt I, Woolley E. A Multi-sensor Approach for Fouling Level Assessment in Clean-in-place Processes. Procedia CIRP [Internet]. 2016 [cited 2016 Nov 7];55:134-9. Available from: http://www.sciencedirect.com/science/article/pii/S2212827116307685

22. Simeone A, Segreto T, Teti R. Residual stress condition monitoring via sensor fusion in turning of Inconel 718. In: Procedia CIRP. 2013.

23. Simeone A, Woolley EB, Rahimifard S. Tool State Assessment for Reduction of Life Cycle Environmental Impacts of Aluminium Machining Processes via Infrared Temperature Monitoring. Procedia CIRP [Internet]. 2015 [cited 2015 Jul 10];29:52631. Available from: http://www.sciencedirect.com/science/article/pii/S2212827115001134

24. Gould O, Simeone A, Colwill J, Willey R, Rahimifard S. A Material Flow Modelling Tool for Resource Efficient Production Planning in Multi-product Manufacturing Systems. Procedia CIRP [Internet]. 2016 [cited 2016 Feb 19];41:21-6. Available from: http://www.sciencedirect.com/science/article/pii/S2212827116000111

25. Dorigo M, Gambardella LM. Ant colony system: A cooperative learning approach to the traveling salesman problem. IEEE Trans Evol Comput. 1997;1(1):53-66.

26. Nash JC. The (Dantzig) simplex method for linear programming. Comput Sci Eng [Internet]. 2000;2(63):29-31. Available from: papers2://publication/uuid/78A6576D69E0-4E03-82CC-6282C9BF47EC

27. Hestenes MR, Stiefel E. Methods of conjugate gradients for solving linear systems. J Res Natl Bur Stand (1934) [Internet]. 1952;49(6):409. Available from: http://nvlpubs.nist.gov/nistpubs/jres/049/jresv49n6p409_A1b.pdf

28. Goldberg DE. Genetic Algorithms in Search, Optimization, and Machine Learning 
[Internet]. Vol. Addison-We, Addison Wesley. 1989. 432 p. Available from: http://www.mendeley.com/research/genetic-algorithms-in-search-optimization-andmachine-learning/

29. Dorigo M, Maniezzo V, Colorni A. Ant system: Optimization by a colony of cooperating agents. IEEE Trans Syst Man, Cybern Part B Cybern. 1996;26(1):29-41.

30. Andrews KR. The Concept of Corporate Strategy [Internet]. Resources, Firms, and Strategies: A Reader in the Resource-based Perspective. 1997. p. 52-9. Available from:

http://books.google.at/books/about/Resources_Firms_and_Strategies.html?id=Zj7JwM cMoY0C\&redir_esc=y

31. Woolley E, Sheldrick L, Arinez J, Rahimifard S. Extending the boundaries of energy management for assessing manufacturing business strategies. 2013;

32. Simeone A, Luo Y, Woolley E, Rahimifard S, Bo?r C. A decision support system for waste heat recovery in manufacturing. CIRP Ann - Manuf Technol. 2016;

33. Palabiyik I, Yilmaz MT, Fryer PJ, Robbins PT, Toker OS. Minimising the environmental footprint of industrial-scaled cleaning processes by optimisation of a novel clean-in-place system protocol. J Clean Prod [Internet]. 2015 Dec [cited 2016 Apr 26];108:1009-18. Available from: http://www.sciencedirect.com/science/article/pii/S0959652615010458

34. Thomas A, Sathian CT. Cleaning-In-Place (CIP) System in Dairy Plant-Review. IOSR J Environ Sci Ver III [Internet]. 2014;8(6):2319-99. Available from: www.iosrjournals.org

35. Jude B, Lemaire E. How to Optimize Clean-in-Place (CIP) Processes in Food and Beverage Operations [Internet]. Schneider Electric White Paper. 2013. Available from: http://www2.schneider-electric.com/documents/support/white-papers/energyefficiency/how-to-optimize-clear-in-place-CIP-processes.pdf

36. Whitehead K a., Smith L a., Verran J. The detection of food soils and cells on stainless steel using industrial methods: UV illumination and ATP bioluminescence. Int J Food Microbiol. 2008;127(1-2):121-8.

37. Otsu N. Threshold selection method from grey-level histograms [Internet]. Vol. SMC9, IEEE Trans Syst Man Cybern. 1979. p. 62-6. Available from: http://www.scopus.com/inward/record.url?eid=2-s2.0-

0018306059\&partnerID=tZOtx3y 1

38. Tukker A. Eight types of product-service system: Eight ways to sustainability? Experiences from suspronet. Bus Strateg Environ. 2004;13(4):246-60.

39. Kara S, Manmek S. Impact of Manufacturing Supply Chain on the Embodied Energy of Products. In: Proceedings of the 43rd International Conference on Manufacturing Systems. Vienna, Austria; 2010. p. 187-94. 